\title{
MBTI PERSONALITY TYPES for CAREER DEVELOPMENT (SMK Santo Lukas - Jakarta)
}

\author{
Andreas Wijaya ${ }^{1)}$, Novita ${ }^{2) *}$ dan Henilia Yulita ${ }^{3)}$ \\ ${ }^{1)}$ Manajemen/Fakultas Ilmu Sosial dan Humaniora, Universitas Bunda Mulia \\ ${ }^{2)}$ Manajemen/Fakultas Ilmu Sosial dan Humaniora, Universitas Bunda Mulia \\ ${ }^{3)}$ Manajemen/Fakultas Ilmu Sosial dan Humaniora, Universitas Bunda Mulia
}

Diterima 05 Agustus 2019 / Disetujui 02 September 2019

\begin{abstract}
Indonesia is a pluralistic country with a population of 269 million. Nowadays, it coincide with exploded population faced with unemployment problem. Based on BPS data, in 2018 the unemployment problem came from high school graduate. This research aim to determine career choices for career planning. The Myers-Briggs Type Indicator (MBTI) is a psychometric personality test that has been widely used to help people choose the career field that best targets the participants are 8th grade students from SMK Santo Lukas North Jakarta, the method psychology through the MBTI test. Measurements were made through questionnaires that contained questions in previous studies with inventory self-report techniques from Cohen for reporting self-condition regarding the lives of one's testicles. The MBTI test was conducted by asking students to obtain a questionnaire, which would then be processed and it is known the personality is then announced with the appropriate type of work. Each result of the questionnaire was submitted and approved, so that all students were satisfied with the learning they had obtained at that time.
\end{abstract}

Keywords: MBTI, ,career, personality, self report inventory

\begin{abstract}
ABSTRAK
Indonesia merupakan negara majemuk dengan jumlah penduduk mencapai 269 juta jiwa. Tingginya jumlah penduduk di suatu negara tidak terlepas dari keberadaan pengangguran. Berdasarkan data BPS, mayoritas pengangguran pada tahun 2018 adalah lulusan SMK. Siswa/i SMK. Tujuan dari penelitian ini adalah diharapkan para siswa/imampu menentukan pilihan karier sejak dini agar pengembangan karir menjadi lebih terencana. The Myers-Briggs Type Indicator (MBTI) dari adalah tes kepribadian psikometris yang telah banyak digunakan untuk membantu orang-orang dalam memilih bidang karir yang paling tepat sasaran peserta adalah siswa/i kelas 8 dari SMK Santo Lukas Jakarta Utara, metode psikologi melalui MBTI test. Pengukuran dilakukan melalui kuesioner yang berisi instrumen pertanyaan pada penelitian dengan teknik self report inventory untuk melaporkan keadaan diri sendiri mengenai kehidupan testitif seseorang. Tes MBTI dilakukan dengan meminta siswa untuk mengerjakan kuesioner, yang kemudian akan diolah dan diketahui kepribadiaannya untuk kemudian dihubungkan dengan jenis pekerjaan yang sesuai. Setiap hasil kuesioner tipe kepribadian siswa dibahas dan diarahkan, sehingga semua siswa merasa puas dengan pembelajaran yang mereka peroleh saat itu.
\end{abstract}

Kata Kunci: MBTI, karir, kepribadian, penilaian diri sendiri

\footnotetext{
*Korespondensi Penulis:

E-mail: Awijaya@bundamulia.ac.id
} 


\section{PENDAHULUAN}

Indonesia merupakan negara majemuk dengan jumlah penduduk mencapai 269 juta jiwa. Jumlah penduduk Indonesia saat ini sebanyak 269 juta jiwa atau 3,49\% dari total populasi dunia. Indonesia berada di urutan keempat dunia setelah Tiongkok, India, dan Amerika Serikat (AS). Berdasarkan data survey Worldometers yang dikutip dalam Katadata (2018), Indonesia saat ini memiliki jumlah penduduk sebanyak 269 juta jiwa atau $3,49 \%$ dari total populasi dunia. Indonesia berada di peringkat keempat negara berpenduduk terbanyak di dunia setelah Tiongkok (1,4 miliar jiwa), India (1,3 miliar jiwa), dan Amerika Serikat (328 juta jiwa). Sebanyak $56 \%$ atau 150 juta jiwa dari penduduk Indonesia adalah masyarakat urban. Jumlah penduduk Indonesia terus tumbuh dari 261,1 juta jiwa pada 2016 menjadi 263,9 juta jiwa pada 2017. Pada 2018, jumlah penduduk Indonesia mencapai 266,7 juta jiwa. Jumlah penduduk dunia saat ini mencapai 7,7 miliar jiwa. Jumlah kelahiran sejak awal tahun ini mencapai sekitar 45 juta jiwa, sedangkan penduduk yang meninggal sekitar 19 juta jiwa.

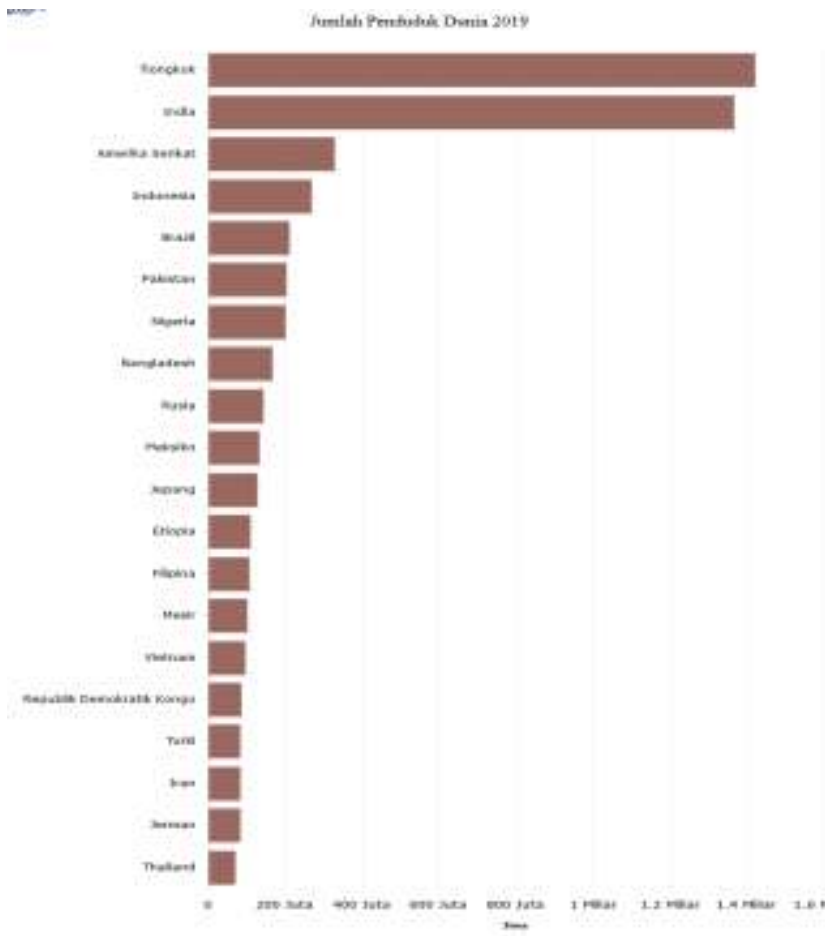

Gambar 1. Jumlah Penduduk Dunia 2018 Sumber :Katadata (2018)
Tingginya jumlah penduduk di suatu negara tidak terlepas dari keberadaan pengangguran. Berdasarkan data BPS, mayoritas pengangguran pada tahun 2018 adalah lulusan SMK. Siswa/i SMK

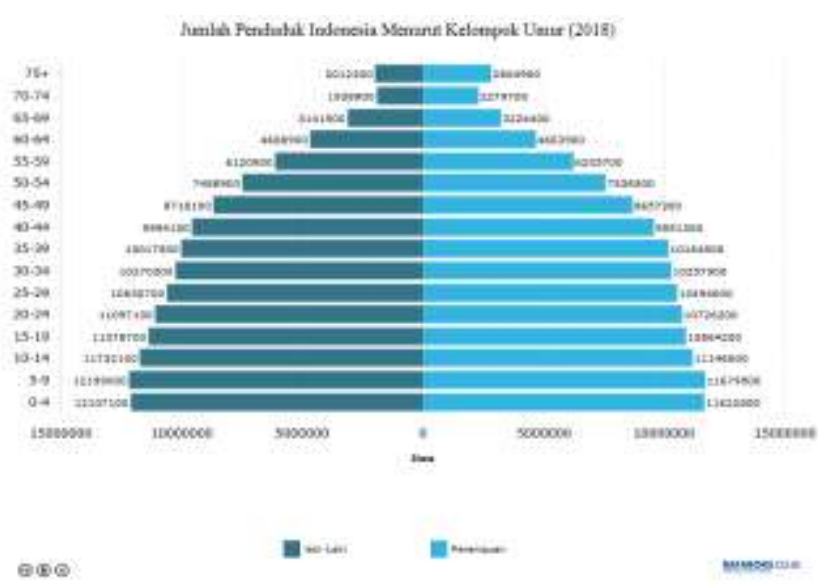

Gambar 2. Jenis Penduduk Indonesia Menurut Kelompok Umur (2018) Sumber :Katadata (2018)

Hal ini pun serupa dengan hasil survey dari Perencanaan Pembangunan Nasional (Bappenas) 2013 jumlah penduduk Indonesia pada 2018 mencapai 265 juta jiwa. Jumlah tersebut terdiri dari 133,17 juta jiwa laki-laki dan 131,88 juta jiwa perempuan. Menurut kelompok umur, penduduk yang masih tergolong anak-anak (0-14 tahun) mencapai 70,49 juta jiwa atau sekitar $26,6 \%$ dari total populasi. Untuk populasi yang masuk kategori usia produktif (14-64 tahun) 179,13 juta jiwa $(67,6 \%)$ dan penduduk usia lanjut 65 ke atas sebanyak 85,89 juta jiwa $(5,8 \%)$. Dari proyeksi tersebut, jumlah kelahiran pada tahun ini mencapai 4,81 juta jiwa sedangkan jumlah kematian 1,72 juta jiwa. Adapun rasio angka ketergantungan (usia produktif terhadap usia nonproduktif) sebesar 47,9\%, lebih rendah dari tahun sebelumnya sebesar 48,1\% dan juga turun dari posisi 2010 yang mencapai 50,5\%. Melihat dari data tersebut, seharusnya siswa/i mampu menentukan pilihan karier sejak dini agar pengembangan karir menjadi lebih terencana. Hal ini dapat dilihat dari data BPS 2018: Jumlah angkatan kerja pada Agustus 2018 sebanyak 131,01 juta orang, naik 2,95 juta orang dibanding Agustus 2017. Komponen pembentuk angkatan kerja adalah penduduk yang bekerja dan pengangguran. Pada Agustus 2018,sebanyak 124,01 juta orang adalah 
penduduk bekerja, sedangkan sebanyak 7 juta orang menganggur. Dibanding setahun yang lalu, jumlah penduduk bekerja bertambah 2,99 juta orang, sedangkan pengangguran berkurang 40 ribu orang. Sejalan dengan naiknya jumlah angkatan kerja. Tingkat Partisipasi Angkatan Kerja (TPAK) juga meningkat. TPAK pada Agustus 2018 tercatat sebesar 67,26 persen, meningkat 0,59 persen poin dibanding setahun yang lalu. Kenaikan TPAK memberikan indikasi adanya kenaikan potensi ekonomi dari sisi pasokan (supply) tenaga kerja.

Namun kenyataannya, sebagian besar dari siswa/i SMK tidak mengetahui karir yang sesuai dengan minat dan bakat mereka. The Myers-Briggs Type Indicator (MBTI) dari Isabel (1995) adalah tes kepribadian psikometris yang telah banyak digunakan untuk membantu orang-orang dalam memilih bidang karir yang paling tepat. Tes ini menawarkan pengertian mendalam akan kelebihan dan minat seseorang agar mereka dapat memilih jenis karir yang diminati. Tes MBTI pada praktiknya mulai banyak digunakan pada bidang manajemen seperti penelitian dari Berr (2000) yang melihat hubungan pereferensi karyawan dengan prilaku manajerial serta secara umum Cunningham, L. (2013) mulai memperhatikan banyaknya perusahaan yang memberikan tes MBTI kepada calon karyawan saat tes masuk kerja untuk melihat personaliti dari masingmasing karyawan terserbut. Melihat banyaknya tes MBTI dilakukan, maka dalam kegiatan pengabdian ini mengambil tema "MBTI personality types for career development" agar para siswa/i dibekali tentang pengetahuan khusus untuk perencanaan karir di masa depan

\section{Identifikasi Masalah}

Pada kegiatan pengabdian kali ini, sasaran peserta adalah siswa/i kelas 8 dari SMK Santo Lukas Jakarta Utara. Hal ini didasarkan pada data Badan Pusat Statistik (BPS) 2018 yang menemukan fakta bahwa mayoritas pengangguran di Indonesia adalah lulusan SMK. Berdasarkan data Badan Pusat Statistik per Februari 2018 : Jumlah angkatan kerja pada Agustus 2018 sebanyak 131,01 juta orang, naik 2,95 juta orang dibanding
Agustus 2017. Sejalan dengan itu, Tingkat Partsipasi Angkatan Kerja (TPAK) juga meningkat 0,59 persen poin. Selain itu tingkat pengangguran lulusan SMK sebanyak 8,92\% sementara lulusan SMA 7,19\%. Tapi pada Agustus 2018, tingkat pengangguran dari lulusan SMK naik menjadi 11,24\%, sementara tingkat pengangguran dari kalangan SMA juga mengalami sedikit kenaikan menjadi $7,95 \%$.

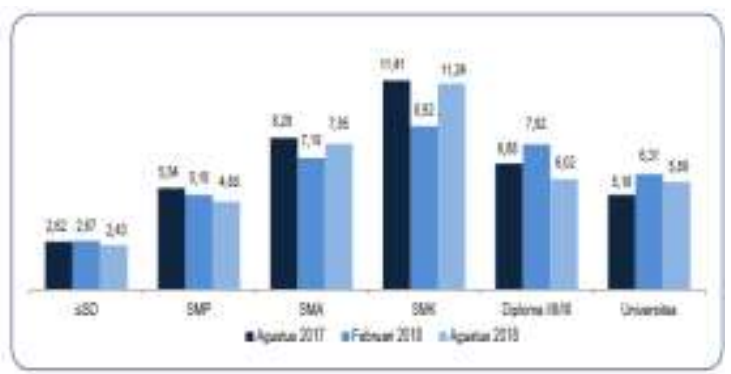

Gambar 3. Tingkat Pengangguran Terbuka (TPT) menurut Pendidikan Tertinggi yang Ditamatkan (persen), Agustus 2017-Agustus 2018

Sumber : BPS 2018

Melihat hal ini, Seharusnya lulusan SMK telah menjadi tenaga kerja siap pakai, di mana setelah lulus sekolah dapat langsung bekerja. Berbeda halnya dengan lulusan SMA, di mana mereka pada dasarnya tidak dibekali oleh keahlian-keahlian khusus karena proses pembelajaran lebih ditujukan untuk pemahaman teori dibandingkan praktek. Kesulitan mendapatkan pekerjaan ini juga dipengaruhi oleh kegagalan siswa/i dalam memilih jenis karir yang sesuai dengan kepribadian atau minat mereka. Pemilihan siswa/i kelas 8 SMK Santo Lukas sebagai sasaran peserta adalah karena perencanaan karir tidak bisa dilakukan secara mendadak. Perencanaan karir membutuhkan pemikiran yang panjang dan membutuhkan waktu minimal satu tahun sebelum masuk ke dunia kerja.

\section{Tujuan dan Manfaat Kegiatan}

Adapun maksud dan tujuan diselenggarakan kegiatan PKM ini adalah untuk :

a. Menambah wawasan tentang penentuan karir yang sesuai dengan kepribadian kepada siswa/i SMK. 
b. Membekali siswa/i SMK tentang perencanaan karir di masa depan.

c. Mempersiapkan diri peserta memasuki jenjang pencarian kerja.

\section{TINJAUAN PUSTAKA}

The Myers-Briggs Type Indicator (MBTI) dari Isabel yang dibuat bersamaan dengan ibu dari Kathrine C Briggs dengan membagi empat fungsi kepribadian manusia.

Menurut Carl Gustav Jung dalam Naisaban (2003) dalam Tes MBTI ini, ada 4 dimensi kecenderungan sifat dasar manusia:

1. Dimensi pemusatan perhatian: Introvert (I) vs. Ekstrovert (E) Dimensi EI melihat sumber energi dari luar atau dalam dirinya.Ekstrovert merupakan tipe kepribadian yang menyukai dunia luar yang senang bergaul, berinteraksi sosial, beraktifitas dengan orang lain, serta berfokus pada dunia luar. Sebaliknya, dimensi introvert menyukai dunia dalam (diri sendiri). Introvert senang menyendiri, merenung, membaca dan tidak begitu suka bergaul dengan banyak orang, mampu bekerja sendiri, penuh konsentrasi serta fokus.

2. Dimensi memahami informasi dari luar : Sensing (S) vs. Intuition (N). imensi SN melihat cara individu memproses data. Tipe sensing memproses data berdasar fakta yang konkrit, praktis, realistis dan melihat data apa adanya. Mereka menggunakan pedoman pengalaman dan data konkrit serta memilih cara-cara yang sudah terbukti. Tipe sensing berfokus pada masa kini. Sementara tipe intuition memproses data dengan melihat pola dan hubungan, pemikir abstrak, konseptual serta melihat berbagai kemungkinan yang dapat terjadi. Mereka berpedoman imajinasi, memilih cara unik, dan berfokus pada masa depan. Tipe intuition sangat inovatif, penuh inspirasi dan ide unik.

3. Dimensi menarik kesimpulan \& keputusan : Thinking (T) vs. Feeling (F)

Dimensi ketiga melihat bagaimana orang mengambil keputusan. Thinking adalah mereka yang selalu menggunakan logika dan kekuatan analisa untuk mengambil keputusan. Mereka cenderung berorientasi pada tugas dan objektif, terkesan kaku dan keras kepala. Tipe thinking menerapkan prinsip dengan konsisten. Sementara feeling adalah mereka yang melibatkan perasaan, empati serta nilainilai yang diyakini ketika hendak mengambil keputusan. Mereka berorientasi pada hubungan dan subjektif. Tipe feeling sering terkesan memihak, mereka empatik dan menginginkan harmoni.

4. Dimensi pola hidup : Judging (J) vs. Perceiving (P). Dimensi terakhir melihat derajat fleksibilitas seseorang. Judging di sini bukan berarti judgemental (menghakimi). Judging diartikan sebagai tipe orang yang selalu bertumpu pada rencana yang sistematis, serta senantiasa berpikir dan bertindak teratur (tidak melompat-lompat). Mereka tidak suka hal-hal mendadak dan di luar perencanaan. Tipe judging ingin merencanakan pekerjaan dan mengikuti rencana itu. Orang dengan dimensi judging bagus dalam penjadwalan, penetapan struktur dan perencanaan step by step. Sementara tipe perceiving adalah mereka yang bersikap fleksibel, spontan, adaptif, dan bertindak secara acak untuk melihat beragam peluang yang muncul. Perubahan mendadak tidak masalah dan ketidakpastian membuat mereka bergairah. Orang dengan dimensi perceiving bagus dalam menghadapi perubahan dan situasi mendadak Menurut Carl Gustav Jung dalam Naisaban (2003) Hasil kombinasi dari 4 dimensi tersebut akan menghasilkan 16 tipe kepribadian, antara lain:

1. ESTJ : 'Extrovert, Sensing, Thinking, Judging

2. ENTJ : Extrovert, Intuition, Thinking, Judging

3. ESFJ : Extrovert, Sensing, Feeling, Judging

4. ENFJ : Extrovert, Intuition, Feeling, Judging

5. ESTP : Extrovert, Sensing, Thinking, Perceiving

6. ENTP : Extrovert, Intuition, Thinking, Perceiving

7. ESFP : Extrovert, Sensing, Feeling, Perceiving

8. ENFP : Extrovert, Intuition, Feeling, Perceiving 
9. INFP : Introvert, Intuition, Feeling, Perceiving

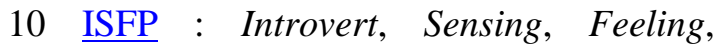
Perceiving

11 INTP : Introvert, Intuition, Thinking, Perceiving

12. ISTP : Introvert, Sensing, Thinking, Perceiving

13. INFJ : Introvert, Intuition, Feeling, Judging

14. ISFJ : Introvert, Sensing, Feeling, Judging

15. INTJ : Introvert, Intuition, Thinking, Judging

16. ISTJ : Introvert, Sensing, Thinking, Judging

\section{METODE PENELITIAN}

Kegiatan pengabdian kepada masyarakat mengambil sampel siswa/i kelas 8 yang berjumlah 48 orang yang dibagi menjadi dua kelompok. Pengabdian ini memadukan pemberian materi yang bertemakan penentuan karir yang tepat sejak dini dan metode psikologi melalui MBTI test. Pengukuran dilakukan melalui kuesioner yang berisi instrumen pertanyaan pada penelitian sebelumnya oleh Fedler (2002) dengan teknik self report inventory dari Cohen (2005) untuk melaporkan keadaan diri sendiri mengenai kehidupan testitif seseorang. Tes MBTI dilakukan dengan meminta siswa untuk mengerjakan kuesioner, yang kemudian akan diolah dan diketahui kepribadiaannya untuk kemudian dihubungkan dengan jenis pekerjaan yang sesuai. Setiap hasil kuesioner tipe kepribadian siswa dibahas dan diarahkan, sehingga semua siswa merasa puas dengan pembelajaran yang mereka peroleh saat itu.

\section{HASIL DAN PEMBAHASAN}

Hasil materi yang diberikan tentang pentingnya penentuan karir yang tepat sejak dini kepada 48 siswa/i SMK Santo, pada sesi pertama para peserta diberikan materi meneganai: "mengenali fungsi utama karir", melalui pembahasan ini diharapkan para siswa/i dapat memenuhi kebutuhan antar manusia, aktivitas, dan pencaharian.

Sesi kedua, pembahasan mengenai "perencanaan karir dan langkah-langkah dalam perencanaan karir"

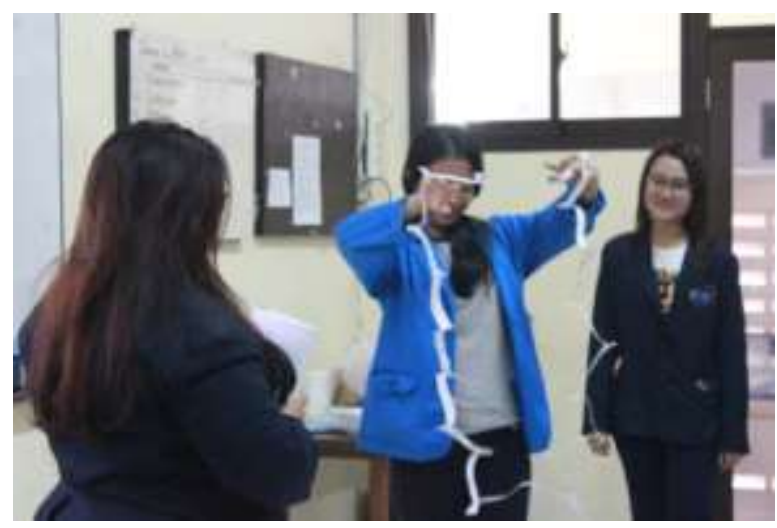

Gambar 4. Sesi Interaktif Langkah-Langkah Perencanaan karir

Sesi ini diberikan kepada siswa/i sebagai masukan agar dapat menjadi bekal untuk menghubungkan pemahaman diri dengan pengetahuan dalam penentuan karir. Pembahasan terakhir pada sesi kedua adalah mengenai "pentingnya kepribadian dalam bekerja membuat sukses dan membuat mimpi yang SMART (spesific, measurable. achievable, relevant, time constraints)" pembahasan ini dilakukan untuk mengetahui kemampuan diri sendiri sekaligus sebagai gambaran untuk menghindari pekerjaan yang tidak cocok di masa yang akan datang.

Sesi ketiga membahas mengenai MBTI (Myers-Birggs Type Indicator). Tes MBTI adalah psikotes yang dirancang untuk mengukur preferensi psikologis seseorang dalam melihat dunia dan membuat keputusan. MBTI didasari pada jenis dan preferensi kepribadian dari Carl Gustav Jung, yang menulis Psychological Types pada tahun 1921 MBTI dikembangkan oleh Isabel Briggs Myers pada sejak 1940. Psikotes ini dirancang untuk mengukur kecerdasan individu, bakat, dan tipe kepribadian seseorang. Tes ini juga dipakai untuk mengetahui karakter kepribadian karyawan perusahaan agar dapat ditempatkan pada bidang-bidang yang membuat potensi karyawan tersebut optimal.

Berdasarkan hasil penelitian sebelumnya dari Carpraro (2002) Hasil dari tes ini akan menunjukkan 4 kecenderungan sifat dasar 
manusia yang dapat digolongkan menjadi 16 kepribadian yaitu:

1. ENFJ dikenal sebagai: "The Givers" (Pemberi) \& "Teacher" (Pengajar). Ciri-ciri: Bersifat hangat, berempati, pendengar yang baik, dan bertanggung jawab. Mereka melihat potensi pada setiap orang, dan ingin membantu mereka untuk mencapai potensi mereka. menurut dimensinya, ENFJ dijelaskan sebagai seseorang yang Extraversion yaitu mereka yang memiliki hubungan atau jaringan perkenalan yang luas.. Intuition yakni mereka yang cenderung menyukai hal abstrak dibandingkan hal detail. Feeling atau perasaan, mereka merupakan orang yang menghargai pertimbangan pribadi. Sedangkan Judgement merupakan mereka yang merencanakan kegiatan barulah menunjukan aksinya. Pekerjaan yang sesuai: Konsultan, Psikolog, Konselor, Pengajar, Marketing, HRD, Event Coordinator, Entertainer, Penulis, Motivator.

2. ENFP dikenal sebagai: "The Inspirers" (Penjiwa) \& "Champion" (Juara) Ciri-ciri: Sosok hangat yang memiliki ansuiasme dan imaginatif. Melihat kehidupan sebagai sesuatu yang penuh kemungkinan. Pekerjaan yang sesuai: Menurut dimensinya Extraversion merupakan seseorang yang bisa berinteraksi dengan luas dan menikmatinya. Intuition yakni cenderung menyukai hal yang abstrak dibanding realita yang ada. Feeling yakni menggunakan pertimbangan pribadi dalam mengambil keputusan dibandingkan logika. Lalu terakhir adalah Perception, dimana mereka cenderung menahan pendapat dan menunda keputusan untuk mencapai kesepakatan bersamaKonselor, Psikolog, Entertainer, Pengajar, Motivator, Presenter, Reporter, MC, Seniman, Hospitality.

3. ENTJ Dikenal sebagai: "The Executives" (Pelaksana) \& "Fieldmarshal" (Panglima). Extroversion atau terbuka dan memiliki hubungan dan jaringan luas dengan siapapun, Intuition yakni orang yang senang akan hal abstrak dan belum jelas tujuannya. Ciri-ciri: Berterus terang, menentukan, siap memikul kepemimpinan. Pekerjaan yang sesuai: Entrepreneur, Pengacara, Hakim, Konsultan, Pemimpin Organisasi, Business analyst, Bidang Finansial.

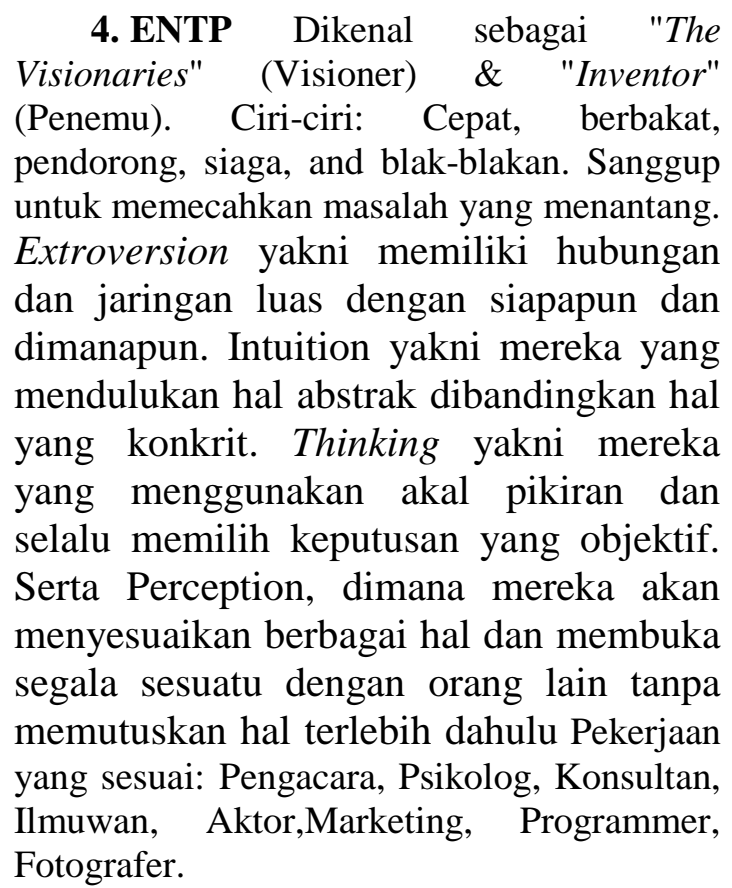

5. ESFJ Dikenal sebagai: "The Caregivers" (Pengasuh) \& "Provider" (Pemberi). Ciri-ciri: Bersahabat,bersungguhsungguh, dan dapat bekerja sama. Dalam dimensinya ESFJ berarti Extroversion, dengan pribadi yang terbuka dan senang dalam berbagi apapun dan memiliki banyak teman. Sensing, dimana mereka menggunakan hal yang konkret dibandingkan hal abstrak atau tidak jelas. Feeling, merupakan pribadi ESFJ dimana mereka menggunakan perasaan pribadi dalam menentukan keputusan, serta Judging. Yakni mereka yang lebih suka membuat perencanaan terlebih dahulu baru menjalankannya Pekerjaan yang sesuai: Perencana Keuangan, Perawat, Guru, Bidang anak-anak,Konselor, Administratif, Hospitality.

6. ESFP Dikenal sebagai: "The Performers" (Pemain) \& "Performer" (Pemain), Ciri-ciri: Sosok yang mencintai 
kehidupan, orang, dan kenyamanan materi. Menurut dimensinya ESFP adalah Extroversion yaitu mereka yang bisa membangun jaringan dengan luas. Sensing, yakni mereka yang tidak suka akan hal abstrak dan lebih suka hal konkret. Kemudian Feeling, yaitu melibatkan masalah pribadi dalam mengambil keputusan dan terakhir yakni Perception. Dimana mereka lebih menyukai kesepakatan yang diambil dibandingkan menjadi seseorang yang merencanakan segala hal lebih dulu. Pekerjaan yang sesuai: Entertainer, Seniman, Marketing, Konselor, Designer, Tour Guide, Bidang Anak-anak, Bidang Hospitality.

7. ESFJ Dikenal sebagai: "The Scientists" (Ahli Keilmuan) \& "Mastermind" (Pengatur). Ciri-ciri: Cepat melihat pola dalam peristiwa yang terjadi disekitar mereka, dan mampu menyusun perspektif jangka panjang yang jelas. Pekerjaan yang sesuai: Peneliti, Ilmuwan, Insinyur, Teknisi, Pengajar, Profesor, Dokter, Research \& Development, Business Analyst, System Analyst, Pengacara, Hakim, Programmers, Posisi Strategis dalam organisasi.

\section{ESTJ Dikenal sebagai: "The} Guardian". Menurut dimensinya ESTJ adalah Extroversion yaitu mereka yang bisa membangun jaringan dengan luas. Sensing, yakni mereka yang tidak suka akan hal abstrak dan lebih suka hal konkret. Kemudian Thinking yakni mereka yang berpikir objektif dalam berbagai hal dan Judging, yakni mereka yang senang membuat rencana dulu baru menjalankannya.Pekerjaan yang sesuai: Polisi, pimpinan militer, petugas keuangan, dan detektif

9. INFJ Dikenal sebagai: "The Protectors" (Pelindung) \& "Counselor" (Penasihat). menurut dimensinya INFJ berarti Introversion atau seseorang yang tidak suka akan hubungan dan dunia luar. Intuition dimana mereka membicarakan hal yang bersifat masa depand an belum jelas atau abstrak. Feeling yaitu mereka memutuskan berbagai hal dengan perasaan dan menyangkut pribadi serta Judging yang mana mereka mengutamakan rencana baru melakukan hal selanjutnya. Ciri-ciri: Pencari makna dan hubungannya dengan ide-ide, hubungan sosial, dan pekerjaan. Pekerjaan yang sesuai: Pengajar, Psikolog, Dokter, Konselor, Pekerja Sosial, Fotografer, Seniman, Designer, Child Care.

10. INTJ Dikenal sebagai: "The Scientists" (Ahli Keilmuan) \& "Mastermind" (Pengatur). menurut dimensinya INTJ berarti Introversion atau seseorang yang tidak suka akan hubungan dan dunia luar. Intuition dimana mereka membicarakan hal yang bersifat masa depand an belum jelas atau abstrak. Thinking merupakan dimensi dasar mereka dimana mereka suka menilai dan berpikir sebelum bertindak dan sangat objektif. Judging merupakan mereka yang merencanakan berbagai hal sebelum bertindak. Ciri-ciri: Memiliki pemikiran yang orisinil dan motivasi yang kuat untuk menerapkan ide-ide mereka hingga mencapai tujuan. Pekerjaan yang sesuai: Peneliti, Ilmuwan, Insinyur, Teknisi, Pengajar, Profesor, Dokter, Research \& Development.

11. INFP Dikenal sebagai: "The Idealist" (Idealis) \& "Healer" (Penyembuh). Ciri-ciri: Idealis, setia kepada prinsip yang mereka genggam serta orang-orang yang penting bagi mereka. Menurut dimensinya INFP berarti Introversion atau seseorang yang tidak suka akan hubungan dan dunia luar. Intuition dimana mereka membicarakan hal yang bersifat masa depan dan belum jelas atau abstrak. Feeling yaitu mereka memutuskan berbagai hal dengan perasaan dan menyangkut pribadi serta Perception yakni pemikiran yang terbuka dan cenderung menunda keputusan demi kesepakatan. Ingin kehidupan yang selaras dengan prinsip yang mereka genggam. Pekerjaan yang sesuai: Penulis, Sastrawan, Konselor, Psikolog, Pengajar, Seniman, Rohaniawan, Bidang Hospitality.

12. INTP Dikenal sebagai: "The Thinkers" (Pemikir) \& "Architect" (Arsitek). Ciri-ciri: Berusaha membangun penjelasan yang masuk akal untuk segala sesuatu yang menarik bagi mereka. Menurut dimensinya INTP yakni Introversion yaitu orang yang senang akan hal yang tenang dan tidak terlalu suka mengenal dunia luas. Intuition, yakni 
mereka yang sebenarnya menyukai hal abstrak dan berkaitan dengan masa depan. Thinking yaitu mereka yang berpikir objektif tanpa melihat siapapun itu, dan Perception dimana mereka membuat keputusan berdasarkan kesepakatan. Pekerjaan yang sesuai: Ilmuwan, Fotografer, Programmer, Ahli komputer, System Analyst, Penulis Buku Teknis, Ahli Forensik, Jaksa, Pengacara, Teknisi.

13. ISFJ Dikenal sebagai: "The Nurturers" (Pengasuh) \& "Protector" (Pelindung). Ciri-ciri: Tenang, ramah, bertanggung jawab, dan teliti. Berkomitmen dan bersungguh-sungguh dalam memenuhi kewajibannya. Menurut dimensinya ISFJberarti Introversion atau seseorang yang tidak suka akan hubungan dan dunia luar. Sensing yaitu mereka yang mengenal hal-hal secara konkret atau nyata. Feeling yaitu mereka memutuskan berbagai hal dengan perasaan dan menyangkut pribadi serta Judging yang mana mereka mengutamakan rencana baru melakukan hal selanjutnya Pekerjaan yang sesuai: Architect, Interior Designer, Perawat, Administratif, Designer, Child Care, Konselor, Back Office Manager, Dunia Perhotelan.

14. ISFP Dikenal sebagai: "The Artist" (Seniman) \& "Composer" (Pengarang). menurut dimensinya ISFP berarti Introversion atau seseorang yang tidak suka akan hubungan dan dunia luar. Sensing yaitu mereka yang mengenal hal-hal secara konkret atau nyata. Feeling yaitu mereka memutuskan berbagai hal dengan perasaan dan menyangkut pribadi serta Perception yakni pemikiran yang terbuka dan cenderung menunda keputusan demi kesepakatan.Ciriciri:Tenang, ramah, sensitif, dan baik hati. Menikmati apa yang sedang terjadi saat ini, apa yang terjadi di sekitar mereka. Pekerjaan yang sesuai: Seniman, Designer, Pekerja Sosial, Konselor, Psikolog, Guru, Aktor, Bidang Hospitality.

15. ISTJ Dikenal sebagai: "The Duty Fulfillers" (Pekerja Keras) \& "Inspector" (Pengawas). Ciri-ciri:Tenang, serius, meraih kesuksesannya dengan ketelitian dan kehandalannya dalam bekerja. menurut dimensinya ISTJ berarti Introversion atau seseorang yang tidak suka akan hubungan dan dunia luar. Sensing yaitu mereka yang mengenal hal-hal secara konkret atau nyata Thinking merupakan dimensi dasar mereka dimana mereka suka menilai dan berpikir sebelum bertindak dan sangat objektif. Judging merupakan mereka yang merencanakan berbagai hal sebelum bertindak Pekerjaan yang sesuai: Bidang Manajemen, Polisi, Intelijen, Hakim, Pengacara, Dokter, Akuntan (Staf Keuangan), Programmer atau yang berhubungan dengan IT, System Analyst, Pemimpin Militer.

16. ISTP Dikenal sebagai: "The Mechanics" (Mekanik) \& "Crafter" (Pengrajin). Ciri-ciri: Bersikap toleran, dan fleksibel, pengamat yang tenang sampai masalah tampak, kemudian bertindak cepat untuk menemukan solusi yang terbaik. menurut dimensinya ISTP berarti Introversion atau seseorang yang tidak suka akan hubungan dan dunia luar. Sensing yaitu mereka yang mengenal hal-hal secara konkret atau nyata Thinking merupakan dimensi dasar mereka dimana mereka suka menilai dan berpikir sebelum bertindak dan sangat objektif. Perception yakni pemikiran yang terbuka dan cenderung menunda keputusan demi kesepakatan. Pekerjaan yang sesuai: Polisi, Ahli Forensik, Programmer, Ahli Komputer, System Analyst, Teknisi, Insinyur, Mekanik, Pilot, Atlit, Entrepreneur.

Berdasarkan hasil para siswa.i yang cukup antusias ini, ditemukan bahwa pengabdian ini perlu untuk dikembangkan lebih lanjut, agar para siswa/i makin mengerti. Salah satu yang dapat dilakukan adalah mengajak para siswa/i untuk melakukan tes MBTI kembali dilain hari untuk melihat reliabilitas jawaban mereka. Saran untuk peghabdian selanjutnya adalah memberikan konseling untuk simulasi sesi interview dan bekerjasama yang baik terhadap rekan kerja.

\section{SIMPULAN}

Simpulan dari kegiatan pengabdian masyarakat ini yaitu menambah wawasan tentang penentuan karir yang sesuai dengan kepribadian kepada siswa/i SMK, dapat membekali siswa/i SMK tentang perencanaan 
karir di masa depan, serta mempersiapkan diri peserta memasuki jenjang pencarian kerja.

\section{DAFTAR PUSTAKA}

Berr, S. A., Church, A. H., \& Waclawski, J. (2000). The right relationship is everything: Linking personality preferences to managerial behaviors. Human Resource Development Quarterly, 11, 133-157.

Capraro, R. M., \& Capraro, M. M. (2002). Myers-Briggs Type Indicator score reliability across studies: A metaanalytic reliability generalization study. Educational \& Psychological Measurement, 62, 590-602.

Cunningham, L. (2013, April 13). MyersBriggs personality test embraced by employers, not all psychologists. The Seattle Time

Cohen, Ronald dan Swerdlik, M. (2005). Psychological Testing and Assessment: an Introduction to Tests and Measurement. 6th Edition. McGraw-Hill International

Fedler \& Dietsz (2002) The effect of personality types of engineering student and performance attitudes. Journal of enginieering education.

Isabel Briggs Myers \& Peter B. Myers (1995). "Gifts Differing: Understanding Personality Type". Davies-Black Publishing.

https://www.bps.go.id/pressrelease/2018/11/0 5/1485/agustus-2018--tingkatpengangguran-terbuka--tpt--sebesar-534-persen.html

https://databoks.katadata.co.id/datapublish/20 18/05/18/2018-jumlah-pendudukindonesia-mencapai-265-juta-jiwa https://mbti.anthonykusuma.com/hasil/istp 